\title{
Noradrenergic Suppression of Synaptic Transmission May Influence Cortical Signal-to-Noise Ratio
}

\author{
MICHAEL E. HASSELMO, CHRISTIANE LINSTER, MADHVI PATIL, DAVEENA MA, AND MILOS CEKIC \\ Department of Psychology and Program in Neuroscience, Harvard University, Cambridge, Massachusetts 02138
}

\begin{abstract}
Hasselmo, Michael E., Christiane Linster, Madhvi Patil, Daveena Ma, and Milos Cekic. Noradrenergic suppression of synaptic transmission may influence cortical signal-to-noise ratio. $J$. Neurophysiol. 77: 3326-3339, 1997. Norepinephrine has been proposed to influence signal-to-noise ratio within cortical structures, but the exact cellular mechanisms underlying this influence have not been described in detail. Here we present data on a cellular effect of norepinephrine that could contribute to the influence on signal-to-noise ratio. In brain slice preparations of the rat piriform (olfactory) cortex, perfusion of norepinephrine causes a dose-dependent suppression of excitatory synaptic potentials in the layer containing synapses among pyramidal cells in the cortex (layer Ib), while having a weaker effect on synaptic potentials in the afferent fiber layer (layer Ia). Effects of norepinephrine were similar in dose-response characteristics and laminar selectivity to the effects of the cholinergic agonist carbachol, and combined perfusion of both agonists caused effects similar to an equivalent concentration of a single agonist. In a computational model of the piriform cortex, we have analyzed the effect of noradrenergic suppression of synaptic transmission on signal-to-noise ratio. The selective suppression of excitatory intrinsic connectivity decreases the background activity of modeled neurons relative to the activity of neurons receiving direct afferent input. This can be interpreted as an increase in signal-to-noise ratio, but the term noise does not accurately characterize activity dependent on the intrinsic spread of excitation, which would more accurately be described as interpretation or retrieval. Increases in levels of norepinephrine mediated by locus coeruleus activity appear to enhance the influence of extrinsic input on cortical representations, allowing a pulse of norepinephrine in an arousing context to mediate formation of memories with a strong influence of environmental variables.
\end{abstract}

INTRODUCTION

Norepinephrine frequently has been described as changing signal-to-noise ratio within brain structures ( Sara 1985; Servan-Schreiber et al. 1990; Woodward et al. 1979). This phrase is used to describe how iontophoretic application of norepinephrine enhances the response of neurons to synaptic input or sensory stimulation, while reducing the background spontaneous activity of neurons. This change in signal-tonoise ratio has been shown for the response of cortical neurons to sensory stimuli in a range of modalities, including auditory (Foote et al. 1983), somatosensory (Waterhouse and Woodward 1980), and visual (Kasamatsu and Heggelund 1982; Madar and Segal 1980). In addition, recordings from hippocampal pyramidal cells during iontophoretic application of norepinephrine or stimulation of the locus coeruleus (Segal and Bloom 1976) demonstrated reduced neuronal activity during behaviorally irrelevant auditory tones but enhanced excitatory responses to tones indicating food.
These changes in signal-to-noise ratio presumably result from the modulatory effects of norepinephrine on cellular physiology. A number of cellular effects of norepinephrine could contribute to this change in dynamics. Here we focus on the role of the noradrenergic suppression of excitatory synaptic transmission. Studies of the effect of norepinephrine on excitatory synaptic transmission have yielded a range of different results. Norepinephrine has been reported to suppress synaptic transmission in the piriform cortex (Collins et al. 1984; McIntyre and Wong 1986; Vanier and Bower 1993 ) and the neocortex (Dodt et al. 1991). In the hippocampus, some researchers have reported suppression of excitatory postsynaptic potentials (EPSPs) by norepinephrine (Mody et al. 1983; Scanziani et al. 1994; Segal 1982), but other researchers have found no effects on EPSPs (Madison and Nicoll 1988; Mueller et al. 1981), suggesting instead that noradrenergic inhibition of population spikes is due to activation of inhibitory interneurons (Mynlieff and Dunwiddie 1988). These differences partly may be due to differences in the region studied: suppression of transmission was shown at mossy fiber and stratum radiatum synapses in organotypic cultures of region CA3 (Scanziani et al. 1994), which may differ from effects in stratum radiatum of region CA1 (Madison and Nicoll 1988; Mueller et al. 1981). The previous study that showed suppression of transmission in stratum radiatum of region CA1 (Mody et al. 1983) may have found effects due to the use of lower stimulation intensities compared with previous work (Mueller et al. 1981) and the use of higher doses relative to later work (Madison and Nicoll 1988). Other effects that could contribute to changes in signal-to-noise ratio are the suppression of excitatory input to interneurons (Doze et al. 1991) and the direct depolarization of interneurons, the latter of which has been inferred from increases in the frequency of spontaneous inhibitory potentials (Doze et al. 1991; Gellman and Aghajanian 1993).

Noradrenergic suppression of excitatory synaptic transmission may be similar to the suppression induced by activation of muscarinic acetylcholine receptors (Hasselmo and Bower 1992) and $\gamma$-aminobutyric acid-B $\left(\mathrm{GABA}_{\mathrm{B}}\right)$ receptors (Tang and Hasselmo 1994), both of which show a laminar selectivity with stronger effects on intrinsic versus afferent fiber synaptic transmission. Norepinephrine also has postsynaptic effects similar to acetylcholine, including the suppression of pyramidal cell adaptation (Barkai and Hasselmo 1994). In behavioral studies, combined blockade of both muscarinic and noradrenergic receptors appears to influence memory function more strongly than blockade of individual receptors (Decker et al. 1990; Kobayashi et al. 
1995 ), and amphetamines can decrease the encoding impairment caused by acetylcholine receptor blockade (Mewaldt and Ghonheim 1979). Studies on the primary visual cortex of cats suggests that both modulators are necessary for formation of ocular dominance columns during the critical period of visuocortical development (Bear and Singer 1986). Therefore, it is of interest to compare the dose-response characteristics and laminar selectivity of norepinephrine with the effects of cholinergic agonists and to measure the interaction of these two modulators.

Here we present data showing selective suppression of excitatory synaptic transmission by norepinephrine in the piriform cortex, and we show how this cellular effect of norepinephrine can enhance signal-to-noise ratio in a computational model by altering the relative influence of recurrent excitation mediating the internal interpretation of sensory input.

\section{METHODS}

\section{Brain slice physiology}

Experiments were performed on brain slice preparations of the piriform cortex from albino Sprague-Dawley rats using standard techniques (Hasselmo and Barkai 1995; Hasselmo and Bower 1991, 1992). Rats were anesthetized with halothane and decapitated. Brains were removed from the skull and mounted on a vibratome for slicing of $400-\mu \mathrm{M}$ thick coronal slices (i.e., perpendicular to the laminar organization of the piriform cortex). Slices were maintained at room temperature in the following solution (in $\mathrm{mM}$ ): $26 \mathrm{NaHCO}_{3}, 124 \mathrm{NaCl}, 5 \mathrm{KH}_{2} \mathrm{PO}_{4}, 2.4 \mathrm{CaCl}_{2}, 1.3 \mathrm{MgSO}_{4}$, and 10 glucose and bubbled with $95 \% \mathrm{O}_{2}-5 \% \mathrm{CO}_{2}$ for a minimum of $1.5 \mathrm{~h}$ before recording. The same solution was perfused through the slice chamber during recording.

For recording, the slice was mounted on a nylon grid in a standard submersion-type slice chamber, with temperature maintained at $35^{\circ} \mathrm{C}$ using a temperature controller. Stopcocks and an isometric pump were used to maintain the superfusion of bathing medium at $\sim 3 \mathrm{ml} / \mathrm{min}$.

Extracellular field potential recordings were obtained with electrodes of $\sim 5 \mathrm{M} \Omega$ impedance containing $3 \mathrm{M}$ sodium chloride. The laminar segregation of afferent and intrinsic fibers in this region allowed differential stimulation of either the afferent input from the lateral olfactory tract (LOT: layer Ia) or the association connections between cortical pyramidal cells (layer Ib), as shown in Fig. 1. Bipolar tungsten stimulating electrodes were guided visually into either the afferent fiber layer (layer Ia) or the association fiber layer (layer $\mathrm{Ib}$ ) and adjusted to obtain clear postsynaptic potentials. Recording electrodes were placed in the layer being stimulated. Layer Ia is differentiated easily from layer Ib because of its greater opacity, while the greater translucence of the cellular layer II can be used to identify the lower border of layer Ib. To ensure maximum segregation of field potential responses, the layer Ia electrodes were placed very high in the layer, among the myelinated fibers in layer Ia, while layer Ib electrodes were placed close to the layer II cell bodies. Stimulation duration was of $0.1 \mathrm{~ms}$, and stimulus amplitude was between 0.08 and $0.45 \mathrm{~mA}$ in layer Ia and between 0.009 to $0.35 \mathrm{~mA}$ in layer $\mathrm{Ib}$.

Single pulse stimulation to layer Ia and Ib was delivered using a Neurodata PG4000 throughout the experiment. The interstimulus interval was $10 \mathrm{~s}$. To measure the effects of carbachol and norepinephrine, extracellular postsynaptic potentials (PSPs) first were amplified using a WPI differential preamplifier and then recorded continuously before, during, and after perfusion of the drug(s) using custom written software on a 386 computer. Peak height was measured from traces averaged during a period of $100 \mathrm{~s}$ (10 trials).

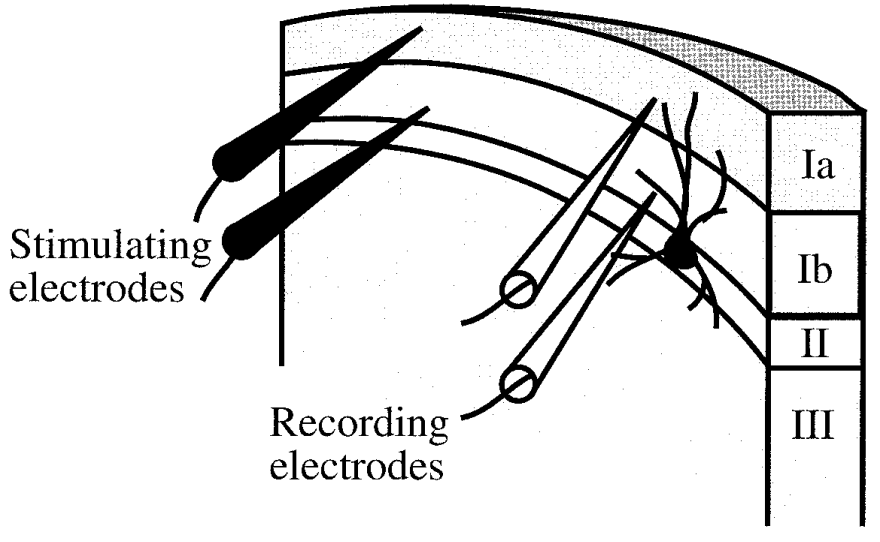

FIG. 1. Schematic representation of brain slice preparation of piriform cortex. Stimulating electrodes were placed among afferent fibers from the lateral olfactory tract (LOT) in layer Ia or among intrinsic and association fibers in layer Ib. Extracellular recording electrodes were used to record synaptic potentials from the layer being stimulated.

When initially obtained, the synaptic potentials were elicited for 10-34 min to determine that they had stabilized, and a baseline height was measured. For measurement of the dose-response curve for norepinephrine, the chamber then was perfused until peak suppression was determined to have been reached (10-12 min) after which perfusion with normal solution was resumed. The washout with normal solution was considered completed when the peak height was within the range of $90-100 \%$ of the baseline level.

Measurement of the interaction of cholinergic and noradrenergic modulation involved sequential perfusion of the slice chamber with norepinephrine and with the cholinergic agonist carbachol. Carbachol was used because of its resistance to breakdown by acetylcholinesterase. Use of acetylcholine requires fast application or blockade of endogenous acetylcholinesterase with substances such as neostigmine (Hasselmo and Bower 1992). In these experiments, after a stable baseline height was obtained, the slice chamber was perfused with the following sequence: norepinephrine, washout, carbachol, washout, norepinephrine plus carbachol, washout. A similar set of experiments was performed in the order carbachol, norepinephrine, combination. Data on combined effects of the carbachol and norepinephrine present numbers from these separate experiments.

\section{Computational modeling}

To understand the role of suppression of synaptic transmission by norepinephrine in the piriform cortex, we incorporated the cellular data on effects of norepinephrine into a network simulation of the piriform cortex. This allowed analysis of how these effects can lead to specific functional interpretations. Modeling used a network structure described in previous publications (Linster and Hasselmo 1996, 1997). Simulations were run on a SUN Sparcstation20 using a previously developed software package written in C by Dr. Linster. The network contains populations of neurons representing pyramidal cells and interneurons in the piriform cortex.

This model draws on extensive previous anatomic and physiological research on the olfactory cortex ( see Haberly 1985; Haberly and Bower 1989 for review). The model consists of 50 pyramidal cells and 50 each of feedback and feed-forward interneurons (Fig. 2). Afferent input is given to pyramidal cells and feed-forward interneurons. Each pyramidal cell makes recurrent excitatory connections to 20 surrounding pyramidal cells, the strength of these connections decays linearly as a function of the distance between the two cells. These connections are made via synapses, which elicit synaptic potentials with both fast time courses [ $\alpha$-amino-3-hydroxy-5-methyl- 


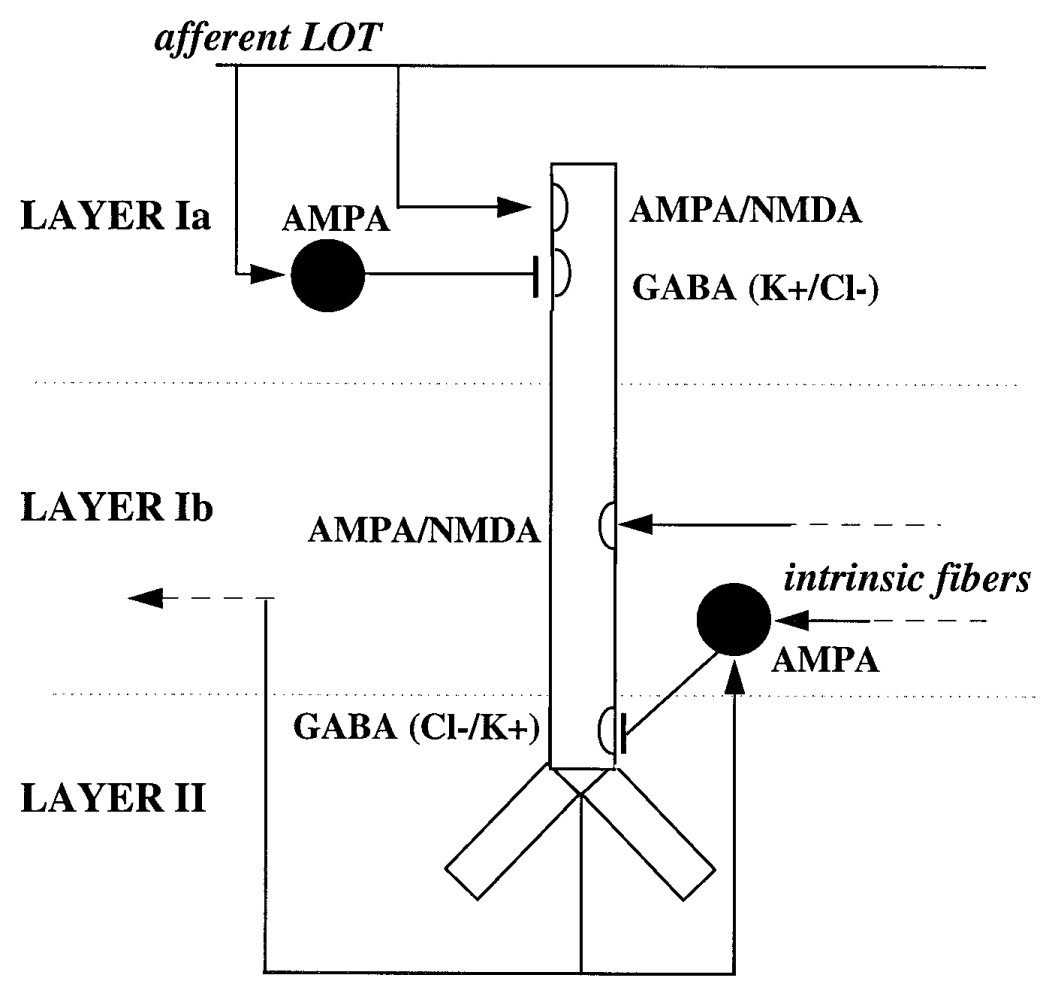

FIG. 2. Architecture of computer simulation of piriform cortex: 50 pyramidal cells each receive input connections from lateral olfactory tract. In addition, 50 feed-forward interneurons also receive input from LOT and inhibit pyramidal cells via $\gamma$-aminobutyric acid-A $\left(\mathrm{GABA}_{\mathrm{A}}\right)$ and $\mathrm{GA}$ $\mathrm{BA}_{\mathrm{B}}$ receptors. In layer $\mathrm{Ib}$, pyramidal cells receive recurrent excitatory input from other pyramidal cells. Pyramidal cells also excite 50 feedback interneurons, which in turn inhibit pyramidal cells. Feedback interneurons inhibit each other via $\mathrm{GABA}_{\mathrm{A}}$ receptors.

4-isoxazolepropionic acid (AMPA)] and slow time courses $[\mathrm{N}-$ methyl-D-aspartate (NMDA)]. Each feed-forward interneuron connects to 10 pyramidal cells. These synapses elicit synaptic potentials with both fast $(20 \%)$ and slow (80\%) time courses representing $\mathrm{GABA}_{\mathrm{A}}$ and $\mathrm{GABA}_{\mathrm{B}}$ receptors. Both time courses have been demonstrated in piriform cortex inhibitory potentials (Tseng and Haberly 1988). Each pyramidal cell connects to five feedback interneurons and receives input from the same five interneurons [via fast ( $80 \%)$ and slow (20\%) synapses]. Feedback interneurons make feedback inhibitory connections among each other (via fast synapses ). A number of differences have been described between superficial and deep pyramidal cells in the piriform cortex (Tseng and Haberly 1989), but this model does not have sufficient detail to address the functional role of this distinction.

Afferent input from the lateral olfactory tract is simulated as 120 -ms bursts of activity to pyramidal cells and feed-forward interneurons. The amplitude of the input signal rises to its maximal value in $20 \mathrm{~ms}$, stays constant for $60 \mathrm{~ms}$, and decays back to baseline during $40 \mathrm{~ms}$. In the simulations described here, five randomly chosen pyramidal cells and feed-forward interneurons received input.

CELLULAR EFFECTS OF NOREPINEPHRINE. A range of cellular effects of norepinephrine were incorporated in the model, including the physiological data described here. Effects of norepinephrine included the following: suppression of intrinsic excitation (feedback excitation ) - as presented here, suppression of pyramidal cell input to inhibitory interneurons (feedback inhibition) (Doze et al. 1991), and depolarization of inhibitory interneurons (Doze et al. 1996; Gellman and Aghajanian 1993). In the simulations, we analyze the effects on signal-to-noise ratio of variable degrees of suppression of feedback excitation and feedback inhibition. In addition, we analyze the effect of depolarization of inhibitory interneurons by $5 \mathrm{mV}$.

SIGNAL-TO-NOISE RATIO. To test the enhancement of signal-tonoise ratio, a network with initial random connectivity was presented with randomly chosen sets of input patterns. Each input pattern consisted of continuous input to five pyramidal cells and feed-forward interneurons during $120 \mathrm{~ms}$. The response of the network was analyzed to determine how much neuronal activity depended on afferent input and how much was due to "spontaneous" background activity. Activity was tested with varying levels of suppression of feedback excitation and inhibition.

For each point in parameter space, we ran simulations with 50 randomly chosen input patterns. The signal-to-noise ratio as we define it here is the ratio of the average number of spikes elicited in pyramidal cells receiving direct afferent input divided by the average of the total number of spikes in all neurons during the stimulus presentation.

IMPLEMENTATION. In the simulations, the resting potentials of neurons was used as the reference potential [i.e., resting potential is modeled as $v(0)=0.0$ ]. The evolution of interneuron membrane potential $v(t)$ around resting potential was described by a first order differential equation

$$
\tau \frac{\mathrm{d} v(t)}{\mathrm{d} t}+v(t)=I(t)
$$

where $t$ is the charging time constant of the neuron, and $I(t)$ is the total change in postsynaptic membrane potential due to synaptic input at time $t$. Time constants were set at $20 \mathrm{~ms}$ for pyramidal cells and $5 \mathrm{~ms}$ for interneurons. All neurons were spiking. At each time step $t$, the probability $P$ for a spike to be generated was a linear threshold function with saturation at a probability of 1.0 for high membrane potentials. The linear increase in spiking probability starts at $\theta_{\min }$ (the spiking threshold), and saturates at $\theta_{\max }$

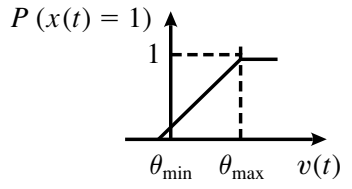

In the simulations presented here, $\theta_{\min }=-0.1$ and $\theta_{\max }=8.0$ $\mathrm{mV}$ for all neurons. Thus in the absence of external input, neurons had a spiking probability of $1.2 \%$, and they reach their maximal 
spike rate when their total depolarization was $\sim 8 \mathrm{mV}$ above resting membrane potential. After occurrence of each spike, the membrane potential was reset to resting potential.

The principal neurons, the pyramidal cells, were composed of three elements: distal dendrites located in layer Ia, the proximal dendrites located in layer Ib, and the soma, located in layer II. Each element received distinct synaptic input and made synapses with interneurons: the distal dendrites received excitatory afferent input from the lateral olfactory tract and inhibitory input from feedforward interneurons; the proximal dendrites received recurrent excitatory input from other pyramidal cells; the soma received inhibitory input from feedback interneurons. Spikes were initiated in the soma as a function of the resulting membrane potential.

In each pyramidal cell element $j$, the evolution of the membrane potential was computed as a function of the membrane potential of the connecting compartments $i$ and of the changes resulting from synaptic input $I(t)$

$$
\tau \frac{\mathrm{d} v_{j}(t)}{\mathrm{d} t}+v_{j}(t)=v_{i}(t)+I(t)
$$

At the soma, spikes were initiated according to the probability function described above for interneurons.

The total input $I_{j}(t)$ to each element $j$ is the weighted sum of changes in membrane potentials elicited at each synapse $i$

$$
I_{j}(t)=\sum_{i} w_{j i}\left[E_{c i}-v_{j}(t)\right] V_{i}(t)
$$

where $V_{i}(t)$ is the change in membrane potential due to presynaptic transmitter release at synapse $i$, which is weighted by the difference between the Nernst potential $E_{c i}$ and the current postsynaptic membrane potential $v_{j}(t)$, and $w_{j i}$ is the connection strength of the synapse. Nernst potentials are $70 \mathrm{mV}$ above resting membrane potential for AMPA- and NMDA-type synapses, and $0 \mathrm{mV}$ and $-15 \mathrm{mV}$ for $\mathrm{GABA}_{\mathrm{A}^{-}}$and $\mathrm{GABA}_{\mathrm{B}}$-type synapses. The time course of postsynaptic conductance changes $V_{i}(t)$ due to presynaptic transmitter release is described by a dual exponential function

$$
V_{i}(t)=v_{j}\left(t_{0}\right) g_{\mathrm{syn}} \frac{\tau_{1} \tau_{2}}{\tau_{1}-\tau_{2}}\left[-e^{-\left(\mathrm{t}_{0} / \tau_{1}\right)}-e^{-\left(\mathrm{t}_{0} / \tau_{2}\right)}\right]
$$

$v_{j}\left(t_{0}\right)$ is the presynaptic depolarization at time $t_{0}$ where transmitter release was initiated. The parameter $g_{\text {syn }}$ is the maximal conductance, this parameter is usually of unit value if not indicated otherwise.

\section{RES ULTS}

\section{Experimental data}

LAMINAR SPECIFICITY OF NOREPINEPHRINE. Norepinephrine caused selective suppression of excitatory synaptic potentials. As shown in Fig. 3, perfusion of the slice chamber with norepinephrine caused suppression of synaptic potentials elicited in layer Ib. A $10 \mu \mathrm{M}$ norepinephrine solution resulted in an average suppression of $54.3 \% \pm 4.1 \%$ (mean $\pm \mathrm{SE} ; n=12$ ). In contrast, the noradrenergic suppression of synaptic potentials elicited in layer Ia was much weaker than noradrenergic suppression in layer Ib. A 10$\mu \mathrm{M}$ solution of norepinephrine resulted in an average suppression of layer Ia potentials by $24.3 \pm 3.7 \%(n=5)$. However, this noradrenergic suppression in layer Ia was much stronger than the cholinergic suppression of layer Ia synaptic potentials reported in previous experiments (Hasselmo and Bower 1992). Therefore, in our experiments, we directly compared effects of norepinephrine and carbachol on layer Ia synaptic potentials in the same slice. In the same slices that showed a $24.3 \%$ suppression in the presence of $10 \mu \mathrm{M}$ norepinephrine, perfusion of $10 \mu \mathrm{M}$ carbachol caused a suppression of only $4.3 \% \pm 2.3(n=5)$. Thus activation of noradrenergic receptors appears to cause stronger suppression of afferent fiber synaptic transmission than the suppression caused by activation of muscarinic receptors.

DOSE-RESPONSE CURVE FOR NOREPINEPHRINE. The dose response curve for norepinephrine is shown in Fig. 4. At 1 $\mu \mathrm{M}$, norepinephrine suppressed $\mathrm{Ib}$ synaptic potentials by $7.1 \pm 1.9 \%(n=7), 5 \mu \mathrm{M}$ norepinephrine suppressed $\mathrm{Ib}$ synaptic potentials by $49.3 \pm 4.9 \%(n=11)$, and, as noted above, $10 \mu \mathrm{M}$ norepinephrine solution caused suppression of $54.3 \pm 4.1 \%(n=12)$. However, when tested at 100 $\mu \mathrm{M}$, norepinephrine caused suppression not much stronger than the $10 \mu \mathrm{M}$ effect, decreasing potentials by only $59.9 \% \pm 2.1(n=5)$.

COMPARISON OF NOREPINEPHRINE EFFECTS WITH CHOLINERGIC AGONIST EFFECTS. Figure 5 plots the dose response curve for norepinephrine against the dose response curve for carbachol obtained in previous research (Hasselmo and Bower 1992). As can be seen in Fig. 5, the IC50 for norepinephrine ends up being similar to that of carbachol, but the plot for norepinephrine is steeper, with different effects at lower and higher doses. Norepinephrine had a weaker effect in layer Ib at the $1-\mu \mathrm{M}$ dose [norepinephrine: $7.1 \%$ vs. carbachol: $23.8 \% \pm 4.1(n=7)$, but its effect was similar to carbachol at $5 \mu \mathrm{M}$ (norepinephrine: $49.3 \%$, carbachol: $45.0 \% \pm 6.9(n=6)]$. At $100 \mu \mathrm{M}$, norepinephrine again had a weaker effect than that of carbachol (norepinephrine: $59.9 \%$, carbachol: $68.6 \%$.

COMBINED EFFECTS OF NOREPINEPHRINE AND ACETYLCHOLINE. The combined influence of these two modulators was analyzed in a set of experiments involving perfusion with the following protocol: control, norepinephrine, washout, carbachol, washout, norepinephrine and carbachol combined, and washout. An alternate set of experiments started presented carbachol first and norepinephrine second. Figure 6 shows synaptic potentials observed during different phases of this experiment. In this set of experiments, $5 \mu \mathrm{M}$ norepinephrine suppressed Ib synaptic potentials by an average of $55.7 \% \pm 7.0(n=6)$ and $5 \mu \mathrm{M}$ carbachol caused a mean suppression of $45.0 \% \pm 6.9(n=6)$. Subsequent perfusion with a combined dose of $5 \mu \mathrm{M}$ norepinephrine and $5 \mu \mathrm{M}$ carbachol resulted in a mean suppression of $64.5 \% \pm 10.3$ $(n=6)$. Thus at this dose, the combined influence of these modulators is stronger than their separate influence. The modulators do not appear to cancel each other out, nor do they appear to have a strong synergistic effect. Rather, combination of $5 \mu \mathrm{M}$ concentrations of each substance appears to have an effect similar to a $10-\mu \mathrm{M}$ dose of one substance. This relationship was less clear at lower doses. As noted above, perfusion of norepinephrine at $1 \mu \mathrm{M}$ caused suppression of $7.1 \% \pm 1.9(n=7)$, perfusion of carbachol caused suppression of $23.8 \% \pm 4.1(n=7)$, whereas perfusion of $1 \mu \mathrm{M}$ norepinephrine combined with $1 \mu \mathrm{M}$ carbachol caused suppression of only $22.2 \% \pm 2.8(n=7)$. Thus the effects of norepinephrine at this low dose may have been too weak to cause an effect stronger than that of carbachol alone. The time course for norepinephrine to cause suppression was slightly longer than that for perfusion of carbachol. When 

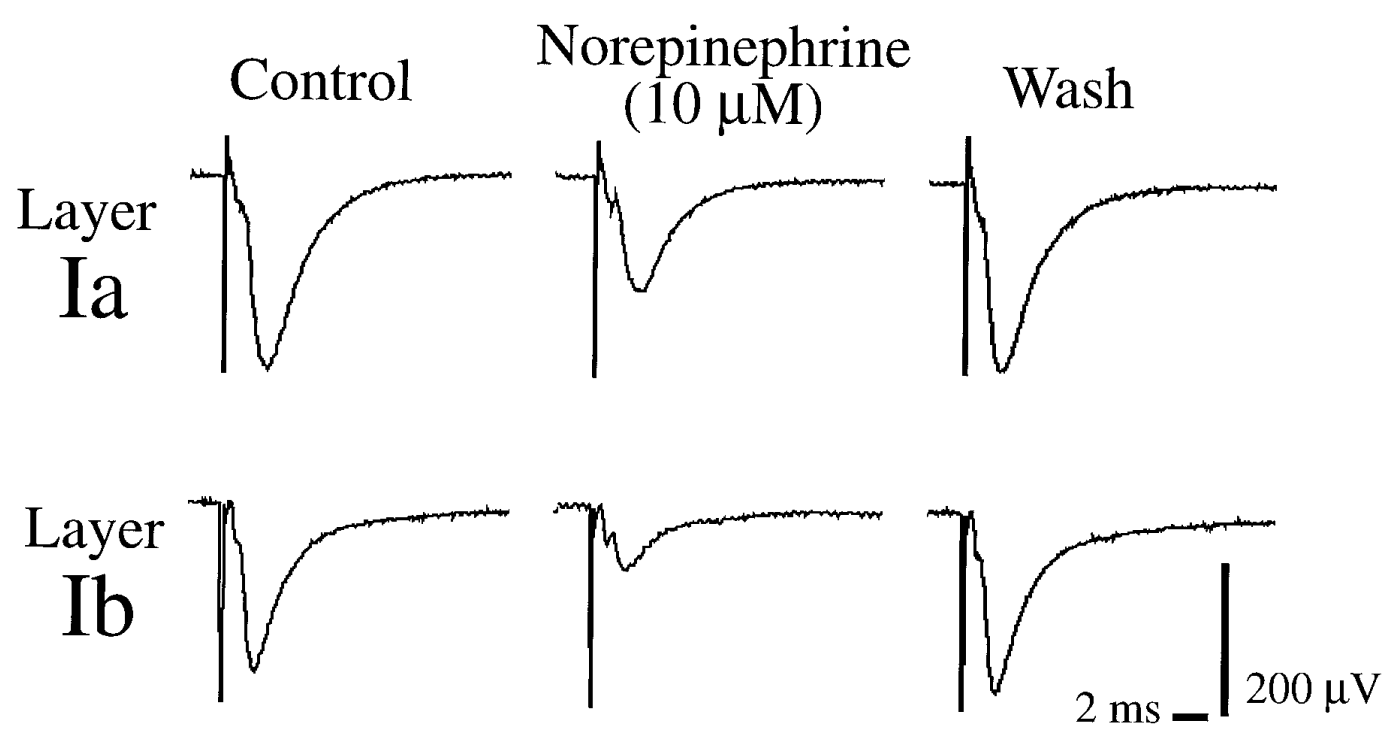

FIG. 3. Suppression of synaptic potentials by norepinephrine is stronger in layer Ib than in layer Ia. Top: evoked synaptic potential in layer Ia recorded before (Control), during, and after (Washout) perfusion with $10 \mu \mathrm{M}$ norepinephrine. Bottom: evoked synaptic potential in layer $\mathrm{Ib}$ recorded before, during, and after perfusion with $10 \mu \mathrm{M}$ norepinephrine. Norepinephrine has a greater effect on intrinsic synaptic potential height.

both agents were perfused, sometimes it was possible to distinguish an early carbachol suppression followed by a slower onset of a norepinephrine effect.

\section{Modeling results}

SUPPRESSION OF FEEDBACK EXCITATION. The computer simulations show that in a network with high background activity, suppression of excitatory transmission between pyramidal cells (feedback excitation) enhances the signal-to-noise ratio. Indeed, suppression of feedback excitation decreases background activity and reduces the recruitment of cells that do not receive direct afferent input. Figure $7 A$ shows membrane potentials and action potentials of 16 pyramidal cells

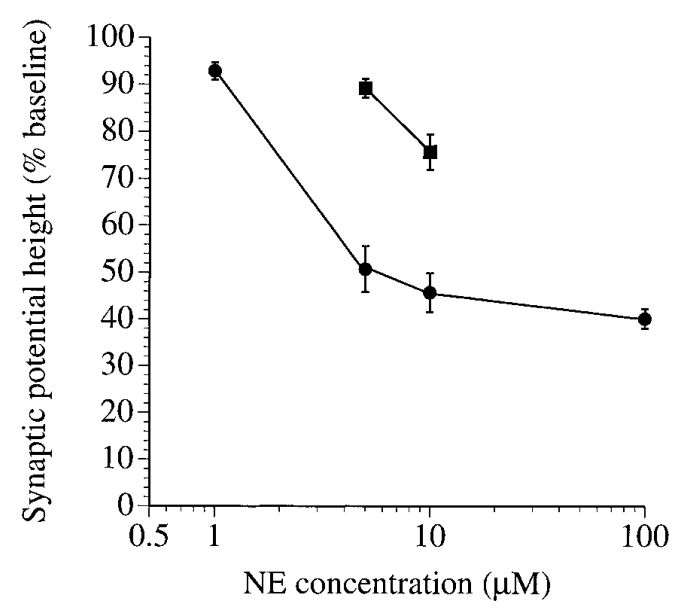

FIG. 4. Dose-response curve for effect of norepinephrine on height of synaptic potentials evoked by afferent stimulation in layer Ia ( $)$ and intrinsic fiber stimulation in layer $\mathrm{Ib}(\bullet)$. Bars represent standard error for recorded data. Responses were recorded extracellularly from layer being stimulated. Concentration of norepinephrine in superfusing medium is plotted logarithmically on abscissa. Extracellular postsynaptic potential (PSP) height in presence of norepinephrine is plotted on ordinate as percent of control PSP height. in the network in response to stimulation in the absence (modulation OFF) and in the presence (modulation ON) of a $60 \%$ suppression of feedback excitation. Pyramidal cells receiving input are indicated by arrows, stimulus onset and offset are indicated by arrowheads below the traces. With no modulation, feedback excitation results in a large number of pyramidal cells showing increased spiking activities during stimulation. In contrast, when feedback excitation is suppressed by $60 \%$, background activity is lower and increases in spike rates are confined primarily to pyramidal cells receiving direct afferent input. Figure $7 B$ shows the average spike rates of each pyramidal cell during spontaneous and stimulus-driven activity in the absence (modulation OFF) and in the presence (modulation ON) of suppression of feedback excitation. For each cell, the average output activity (number of spikes) during $120 \mathrm{~ms}$ is shown in each panel. Pyramidal cells receiving external input are indicated by arrows.

SUPPRESSION OF FEEDBACK INHIBITION. In addition to suppression of intrinsic excitatory synaptic transmission (present results), norepinephrine has been shown to suppress excitatory input from pyramidal cells to inhibitory interneurons in the hippocampus (Doze et al. 1991, 1996). Our simulations show that suppression of excitatory input to interneurons (feedback inhibition), in addition to suppression of feedback excitation, can further enhance signal-to-noise ratio. Figure $8 \mathrm{~A}$ shows membrane potentials and action potentials of 16 pyramidal cells in the network in response to stimulation in the absence (modulation OFF) and in the presence (modulation $\mathrm{ON}$ ) of a $60 \%$ suppression of feedback excitation and $40 \%$ suppression of the excitatory input to inhibitory interneurons (feedback inhibition). Pyramidal cells receiving input are indicated by arrows, stimulus onset and offset are indicated by arrowheads below the traces. With no modulation, feedback excitation results in a large number of pyramidal cells showing increased spiking activities during stimulation. In contrast, when both feedback exci- 


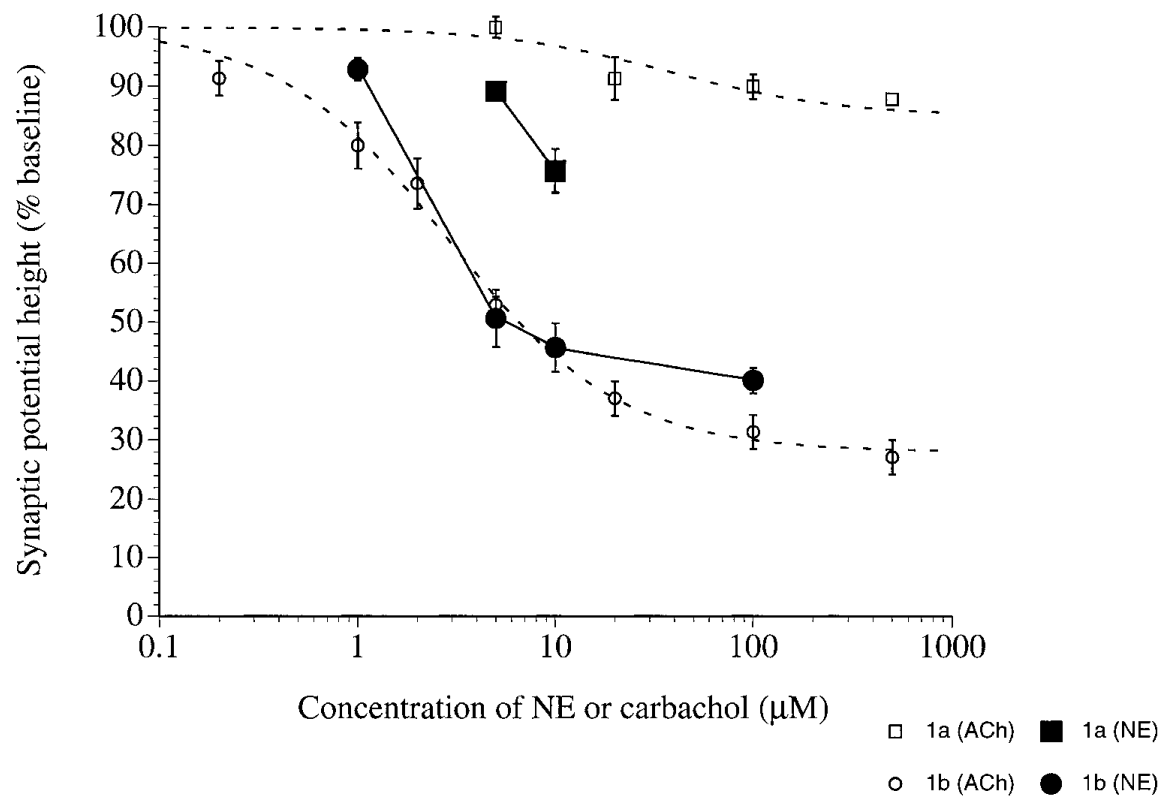

FIG. 5. Dose-response curve for norepinephrine superimposed on curve observed for carbachol in previous experiments (Hasselmo and Bower 1992). Effect of carbachol is stronger at low concentrations and at high concentrations, but IC50 is about equivalent. Effects of norepinephrine are shown for recordings in layer $\mathrm{Ib}(\bullet)$ and in layer Ia ( $\bullet)$. Effects of carbachol are shown for recordings in layer Ib $(\bigcirc)$ and in layer Ia $(\square)$. Dotted lines show doseresponse curves fitted to data for effects of carbachol (Hasselmo and Bower 1992), using standard equation for first-order kinetics $f=(1-x) /\left(1+c / K_{\mathrm{D}}\right)$ $+x$, where $K_{\mathrm{D}}$ was fitted as $2.88 \mu \mathrm{M}$ for layer $\mathrm{Ib}$ and $38 \mu \mathrm{M}$ for layer Ia, and the component resistant to suppression $x$ was fitted as $28 \%$ for layer $\mathrm{Ib}$ and $85 \%$ for layer Ia. tation and feedback inhibition are suppressed, background activity is lower and only pyramidal cells receiving external input have increased spike rates. In this case, pyramidal cells receiving afferent input are more active in the presence of modulation than in the absence of stimulation. Figure $8 B$ shows the average spike rates of each pyramidal cell during spontaneous and stimulus-driven activity in the absence (modulation $\mathrm{OFF}$ ) and in the presence (modulation $\mathrm{ON}$ ) of suppression of feedback excitation. For each cell, the average output activity (number of spikes) during $120 \mathrm{~ms}$ is shown in each panel. Pyramidal cells receiving external input are indicated by arrows. Note that the neurons receiving direct afferent input show higher response in this histogram compared with the histogram presented in Fig. $7 B$.

PARAMETER SPACE. To verify these results, we ran a large number of different simulations with varying amounts of suppression of feedback excitation and feedback inhibition. For each point in parameter space, a new network with random connectivity was constructed, and random input patterns were presented to the network. The signal-to-noise ratio was computed across the full set of different simulations for each parameter value as explained in the methods section. The simulation results show that signal-to-noise ratio is maximal when both feedback excitation and feedback inhibition are suppressed (Fig. 9). Suppression of feedback excitation of $40-60 \%$ led to increased signal-to-noise ratios. When suppression of feedback inhibition also was included, the signal-to-noise ratio was considerably improved. In contrast, modeling the direct noradrenergic depolarization of pyramidal cells and depolarization of interneurons (Gellman and Aghajanian 1993) did not change the observed results (not shown).

ANALYSIS OF A SIMPLIFIED NETWORK MODEL. The simulations presented above used complex connectivity characteristics and spiking neurons to analyze the influence of noradrenergic suppression of synaptic transmission on signal-tonoise ratio. This effect also can be analyzed in a highly simplified network. Here we show a mathematical analysis of the effect of noradrenergic suppression of synaptic transmission in a fully connected network of excitatory pyramidal cells and inhibitory interneurons. These are equivalent to equations representing two excitatory neurons (representing populations of neurons receiving direct afferent input $-s$, and those not receiving afferent input $-n$ ) and an inhibitory neuron (representing the population of inhibitory interneurons in a region). This resembles the network analysis used in previous articles (Hasselmo et al. 1995; Wilson and Cowan 1972), with the threshold linear input-output function replaced by linear input-output functions.

In this example, pyramidal cells receiving afferent input are modeled with the activation variable $s$, pyramidal cells not receiving afferent input are modeled with the activation variable $n$, and interneurons are modeled with the activation variable $i$. If we assume that the number of neurons in the network is large, the connectivity and input $A$ are scaled to the time constants of the neurons, and the input $A$ is present on a time scale much larger than the time constant of the neurons, then we can write the equations for the network as

$$
\begin{gathered}
\tau \frac{\mathrm{d} s}{\mathrm{~d} t}=w_{\mathrm{pp}} s+w_{\mathrm{pp}} n-w_{\mathrm{pi}} i-s+A \\
\tau \frac{\mathrm{d} n}{\mathrm{~d} t}=w_{\mathrm{pp}} s+w_{\mathrm{pp}} n-w_{\mathrm{pi}} i-n \\
\tau \frac{\mathrm{d} i}{\mathrm{~d} t}=w_{\mathrm{pi}} s+w_{\mathrm{pi}} n-i
\end{gathered}
$$

where $A$ is the external afferent input to neurons $s, w_{\mathrm{pp}}$ is the average connection strength between pyramidal cells, $w_{\mathrm{pi}}$ is the average strength of excitatory connections from pyramidal cells to interneurons, and $w_{\text {ip }}$ is the average strength of inhibitory connections from interneurons to pyramidal cells. All connection strengths are normalized between 0 and 1 . Note that we neglect feedback inhibition among interneurons for this example.

We can then calculate the equilibrium state by setting $\mathrm{d} s$ / $\mathrm{d} t=\mathrm{d} n / \mathrm{d} t=\mathrm{d} i / \mathrm{d} t=0$, and replacing $i$ in the equations for $s$ and $n$ 


\section{Layer Ib}

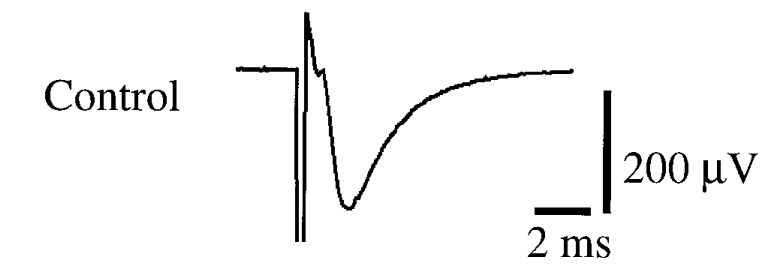

Carbachol $(5 \mu \mathrm{M})$

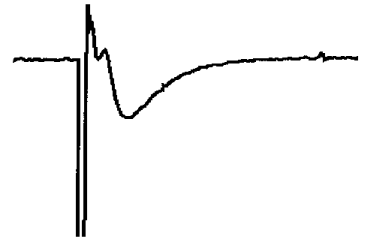

Wash

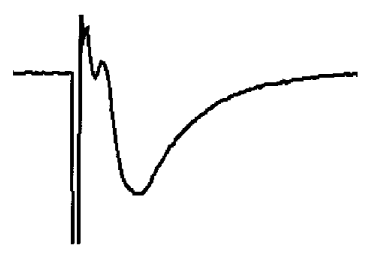

Norepinephrine $(5 \mu \mathrm{M})$

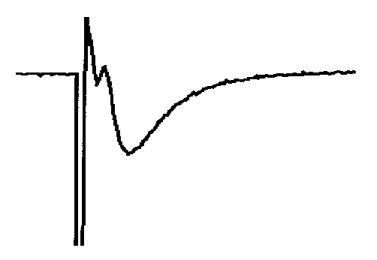

Wash

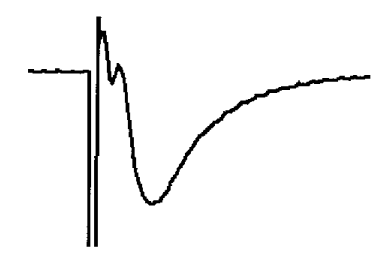

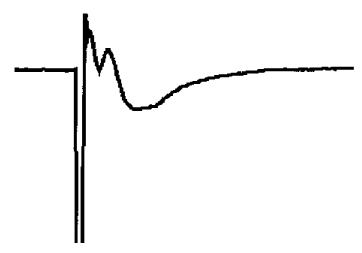

Carbachol $(5 \mu \mathrm{M})+$ Norepinephrine $(5 \mu \mathrm{M})$

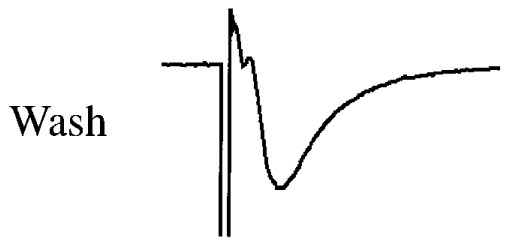

FIG. 6. Synaptic potentials recorded during sequential perfusion and washout of different substances in following order: control, $5 \mu \mathrm{M}$ carbachol, washout, $5 \mu \mathrm{M}$ norepinephrine, washout, combination of $5 \mu \mathrm{M}$ norepinephrine and $5 \mu \mathrm{M}$ carbachol, and final washout. Perfusion during each cycle continued for $12 \mathrm{~min}$.

$$
\begin{gathered}
s=w_{\mathrm{pp}} s+w_{\mathrm{pp}} n-w_{\mathrm{ip}} w_{\mathrm{pi}} s-w_{\mathrm{ip}} w_{\mathrm{pi}} n+A \\
n=w_{\mathrm{pp}} s+w_{\mathrm{pp}} n-w_{\mathrm{ip}} w_{\mathrm{pi}} s-w_{\mathrm{ip}} w_{\mathrm{pi}} n
\end{gathered}
$$

In this network, the signal-to-noise ratio can be analyzed easily as the ratio of $s$ to $n$ (the activation of neurons receiving afferent input to that of neurons not receiving afferent

input. This ratio can be obtained by separating the variables in the equation for steady state value of neurons not receiving afferent input $(n)$, obtaining the following ratio

$$
\frac{s}{n}=\frac{1-w_{\mathrm{pp}}+w_{\mathrm{ip}} w_{\mathrm{pi}}}{w_{\mathrm{pp}}-w_{\mathrm{ip}} w_{\mathrm{pi}}}
$$

Here it can be seen that suppression of recurrent excitation $w_{\mathrm{pp}}$ increases the signal-to-noise ratio, but this effect depends on the relation of $w_{\mathrm{pp}}$ to the product of $w_{\mathrm{ip}}$ and $w_{\mathrm{pi}}$. As can be seen from this equation, the signal-to-noise ratio $s /$ $n$ expressed here tends toward infinity as the value $w_{\mathrm{pp}}$ approaches the product of $w_{\mathrm{ip}}$ and $w_{\mathrm{pi}}$. Note that for the ratio to be positive, $w_{\mathrm{pp}}$ must be greater than the product of $w_{\mathrm{ip}}$ and $w_{\mathrm{pi}}$, and less than $w_{\mathrm{ip}} * w_{\mathrm{pi}}+1$.

In our simulations, $w_{\mathrm{ip}}$ was kept constant, and we varied $w_{\mathrm{pp}}$ and $w_{\mathrm{pi}}$. In the simulations, $w_{\mathrm{ip}}$ was chosen to be 0.6. We have computed the value of $s / n$ for both $w_{\mathrm{pp}}$ and $w_{\mathrm{pi}}$ varying between 0 and 1 . Figure $9 B$ shows the values obtained with the same resolution used in the large scale spiking network simulations described above, illustrating a similar qualitative change in $s / n$ to the change observed in the spiking network model (shown in Fig. 9A). Figure 10 shows a higher resolution surface plot of the output of this equation (note that the plot of $w_{\mathrm{pp}}$ has been reversed to allow better visualization of the surface). In this plot, decreases in $w_{\mathrm{pp}}$ (going leftward) can cause a progressive increase in $s / n$ up to the discontinuity, but the location of this increase depends on the value of $w_{\mathrm{pi}}$. Note that a similar plot would be obtained if $w_{\mathrm{pi}}$ were kept fixed and $w_{\mathrm{ip}}$ were varied.

The signal-to-noise increase in Fig. 10 is a continuous diagonal covering the full range of $w_{\mathrm{pi}}$ values. This suggests that even with no change in $w_{\mathrm{pi}}$, it should be possible to enhance signal to noise just by changing $w_{\mathrm{pp}}$. But the effect on signal to noise with only changes in $w_{\mathrm{pp}}$ was relatively subtle in the spiking network simulation. This is not just due to the interval for sampling the parameters. To explore reasons for the change in $s / n$ across values of $w_{\mathrm{pi}}$, we modified the simple simulation to include firing threshold, a maximum firing rate, and feedback inhibition between inhibitory interneurons. These additional factors make the change in signal-to-noise ratio less consistent across the range of values of $w_{\mathrm{pi}}$, resulting in conditions in which increases of signalto-noise ratio were observed only when suppression of $w_{\mathrm{pp}}$ was combined with suppression of $w_{\mathrm{pi}}$.

The simplified representation also allows analysis of the effect of neuronal adaptation on the steady state signal-to-noise ratio. Modulatory agents have been shown to alter neuronal adaptation in piriform cortex pyramidal cells, particularly in deep pyramidal cells (Tseng and Haberly 1989). In our previous articles (Hasselmo et al. 1995), we modeled adaptation with a buildup of intracellular calcium c proportional to activation of pyramidal cells according to coefficient $\Omega$ and decreasing in proportion to a diffusion coefficient $\gamma$. This influenced activation via an increase in inhibitory current proportional to the coefficient $\mu$ times intracellular calcium, as represented in the following equations

$$
\begin{gathered}
\tau \frac{\mathrm{d} s}{\mathrm{~d} t}=w_{\mathrm{pp}} s+w_{\mathrm{pp}} n-w_{\mathrm{pi}} i-s-\mu c_{\mathrm{s}}+A \\
\tau \frac{\mathrm{d} n}{\mathrm{~d} t}=w_{\mathrm{pp}} s+w_{\mathrm{pp}} n-w_{\mathrm{pi}} i-n-\mu c_{\mathrm{n}}
\end{gathered}
$$


A

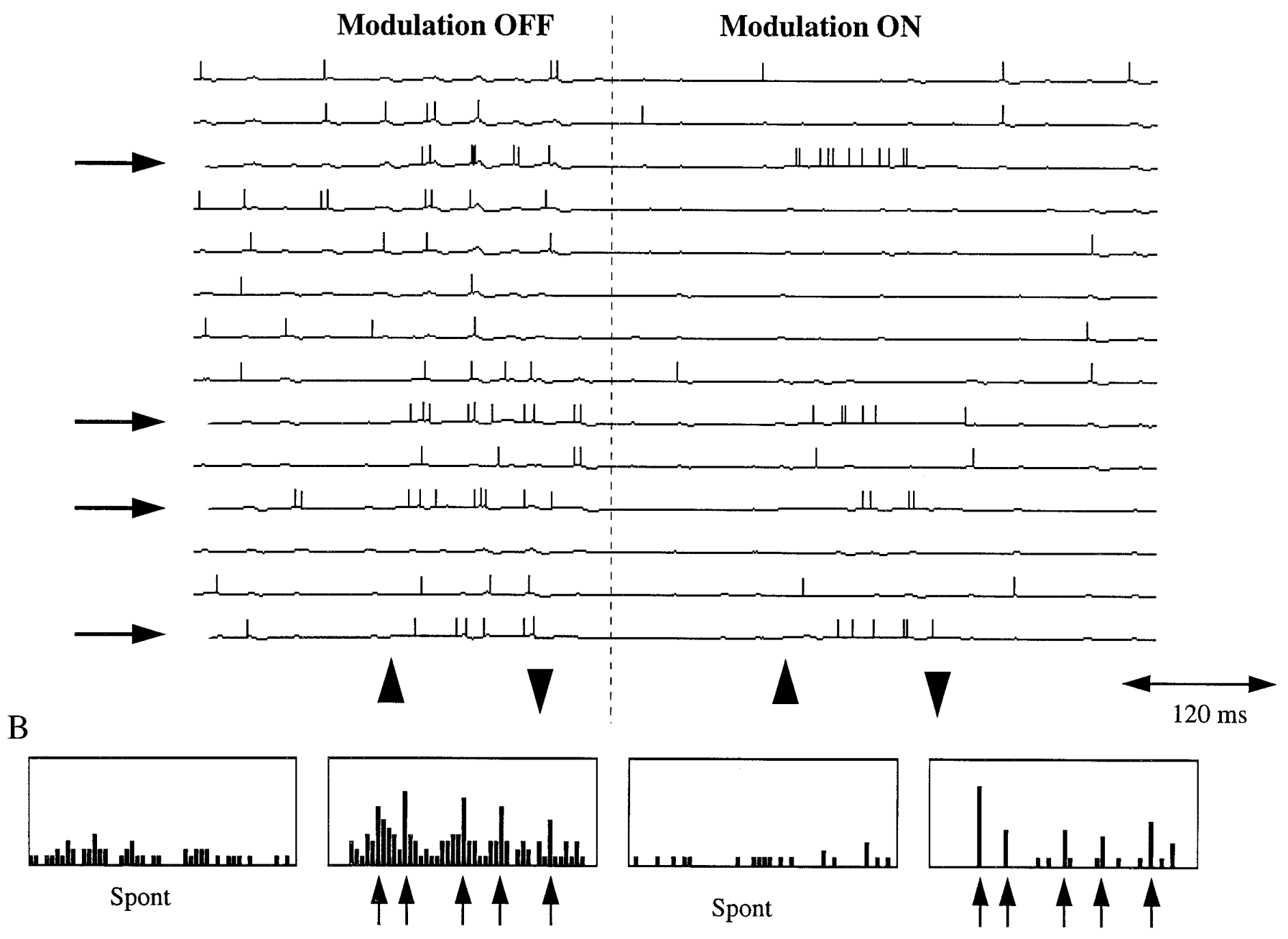

FIG.7. Effect of noradrenergic suppression of feedback excitation on pyramidal cell response to afferent input. $A$ : membrane potentials and action potentials of 16 pyramidal cells are shown. Pyramidal cells receiving afferent input are indicated $(\rightarrow)$. Stimulus onset and offset are indicated $(\mathbf{\Lambda})$. Background activity and response to afferent input are shown in absence (modulation OFF) and in presence (modulation ON) of $60 \%$ suppression of feedback excitation. $B$ : average activities of 50 pyramidal cells in network during 120 -ms background activity (spont) and in response to input. Pyramidal cells receiving input are indicated $(\uparrow)$.

$$
\begin{gathered}
\tau \frac{\mathrm{d} i}{\mathrm{~d} t}=w_{\mathrm{pi}} s+w_{\mathrm{pi}} n-i \\
\frac{\mathrm{d} c_{\mathrm{s}}}{\mathrm{d} t}=\Omega s-\gamma c_{\mathrm{s}}, \frac{\mathrm{d} c_{\mathrm{n}}}{\mathrm{d} t}=\Omega s-\gamma c_{\mathrm{n}}
\end{gathered}
$$

In the steady state, this adds an inhibitory component to each excitatory population dependent on its own activation but not that of the other population. This additional inhibitory component therefore influences only the numerator of the signal-to-noise equation

$$
\frac{s}{n}=\frac{1-w_{\mathrm{pp}}+w_{\mathrm{ip}} w_{\mathrm{pi}}+\mu \Omega / \gamma}{w_{\mathrm{pp}}-w_{\mathrm{ip}} w_{\mathrm{pi}}}
$$

This yields the somewhat paradoxical result that the reduction in adaptation induced by norepinephrine actually should reduce the signal-to-noise ratio due to reduced adaptation of the neurons not receiving direct afferent input. However, this effect on signal-to-noise ratio will appear more slowly due to the slower time constant of neuronal adaptation.

\section{DIS C USSION}

The experimental results presented here demonstrate that norepinephrine suppresses synaptic potentials elicited in the intrinsic fiber layer of the piriform cortex (layer $\mathrm{Ib}$ ) while having a weaker effect on synaptic potentials elicited in the afferent fiber layer (layer Ia). This suggests that noradrenergic modulation acts to decrease excitatory transmission between pyramidal cells in the cortex, while having less influence on the afferent input to the cortex from the olfactory bulb. In a computational model of the piriform cortex, this selective suppression of feedback excitation enhances signalto-noise ratio, increasing the number of spikes generated by pyramidal cells receiving afferent input relative to the number generated by other pyramidal cells in the cortex.

\section{Relation to other physiological data on norepinephrine}

The effects of norepinephrine reported in layer Ib are consistent with previous physiological results from the 
A

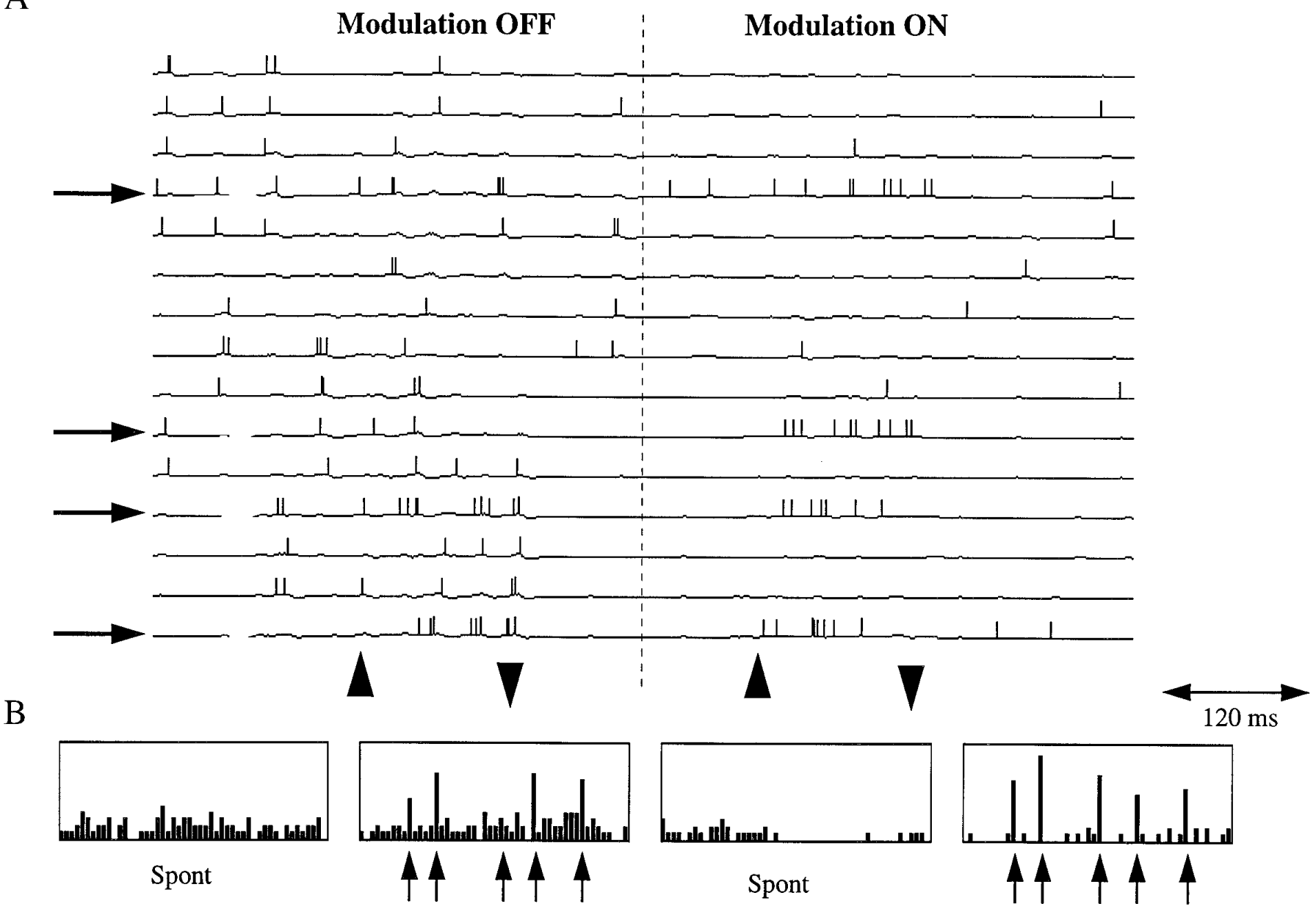

FIG. 8. Effect of noradrenergic suppression of feedback excitation and feedback inhibition on pyramidal cell response to afferent input. $A$ : membrane potentials and action potentials of 16 pyramidal cells are shown. Pyramidal cells receiving afferent input are indicated $(\rightarrow)$. Stimulus onset and offset are indicated $(\mathbf{\Lambda})$. Background activity and response to afferent input are shown in absence (modulation OFF) and in presence (modulation ON) of $60 \%$ suppression of feedback excitation and $40 \%$ of feedback inhibition. $B$ : average activities of 50 pyramidal cells in network during 120 -ms background activity (spont) and in response to input. Pyramidal cells receiving input are indicated $(\uparrow)$. Note greater activity of these neurons compared with those receiving input in Fig. $7 B$.

piriform cortex (Collins et al. 1984; McIntyre and Wong 1986; Vanier and Bower 1992, 1993). We did not observe the increase in synaptic potentials reported during perfusion of high concentrations of norepinephrine in tangential slices (Collins et al. 1984) or in layer Ia in transverse slices (Vanier and Bower 1992). There are a number of differences between the field potentials observed in tangential slices compared with those obtained in transverse slices that could underlie this difference. In fact, the slight reversal of suppression at high doses of norepinephrine observed here could be related to the increase seen in tangential slices. The basis for the difference with previous work in transverse slices is not clear but could be due to differences in stimulation parameters. As described in the INTRODUCTION, differences of stimulus intensity and drug dosage can influence the modulatory change observed (Mody et al. 1983; Mueller et al. 1981), suggesting that norepinephrine may have qualitatively different effects in specific conditions (i.e., depending on the magnitude of cortical activation).
The results presented here are also consistent with some of the data from other cortical structures. Noradrenergic suppression of excitatory synaptic potentials has been reported at the mossy fiber synapse in region CA3 (Scanziani et al. 1994), in stratum radiatum of CA1 (Mody et al. 1983), and in somatosensory cortex (Dodt et al. 1991). However, other researchers have reported that norepinephrine and alpha-adrenergic agonists do not change field EPSP amplitude in hippocampal region CA1 (Madison and Nicoll 1988; Mueller et al. 1981). They suggest that noradrenergic inhibition of population spikes is due to activation of inhibitory interneurons (Mynlieff and Dunwiddie 1988), but this does not address noradrenergic effects on excitatory field potentials (Mody et al. 1983) and intracellularly recorded excitatory synaptic potentials (Dodt et al. 1991; Scanziani et al. 1994). Again, it is possible that these differences result from details of stimulation or dosage or could be due to differences in norepinephrine reuptake mechanisms or receptor desensitization in different slice preparations. 
A

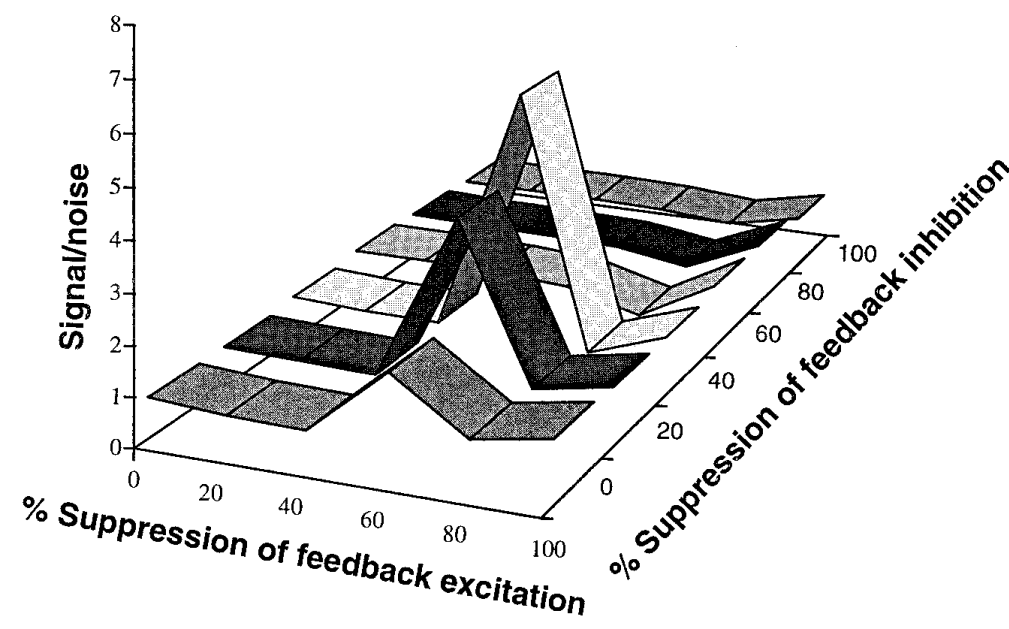

B

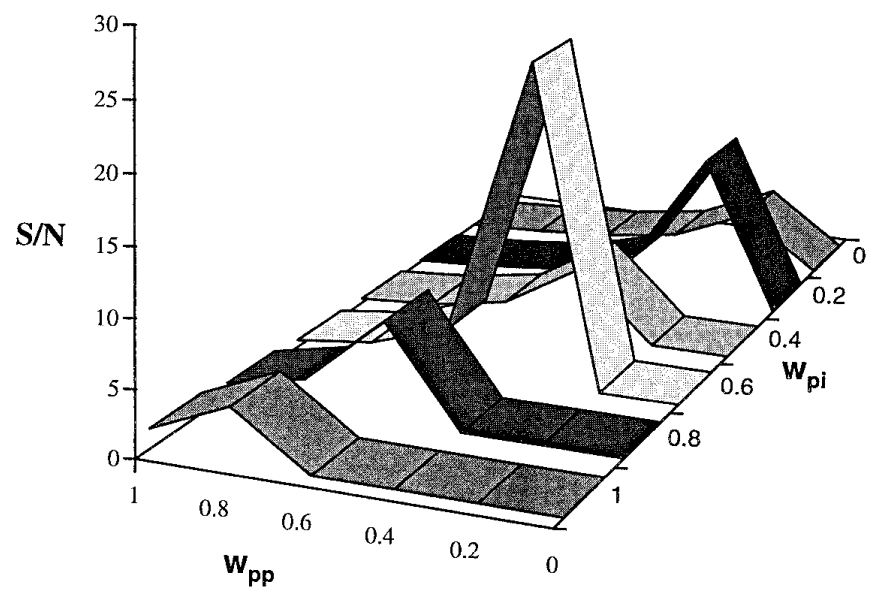

FIG. 9. Signal-to-noise ratio as a function of feedback excitation and inhibition in spiking network model $(A)$ and in simplified mathematical analysis $(B)$. $A$ : for each point in parameter space, 50 networks were constructed and presented with random input patterns. Signal-to-noise ratio is computed as number of spikes generated by neurons receiving input divided by total number of spikes during time of input presentation $(120 \mathrm{~ms}$ ). Suppression of feedback excitation and suppression of feedback inhibition are varied from 0 to $100 \%$ in $20 \%$ steps. Maximal signal-to-noise ratio occurs when feedback excitation is suppressed by $60 \%$ and feedback inhibition by $40 \%$. $B$ : equation for $s / n$ ratio presented in results section was used to generate values of $s / n$ for same parameter values presented for spiking network model. Note a similar qualitative structure to change in signal-to-noise ratio.
The effects of norepinephrine shown here are consistent with the reported antiepileptic effect of noradrenergic agonists. This antiepileptic effect would be surprising if the only influence of norepinephrine were to suppress excitatory input to interneurons or to suppress adaptation in pyramidal cells. Noradrenergic suppression of excitatory intrinsic synaptic transmission could prevent the initiation and spread of runaway excitatory activity in cortical structures, which could contribute to an antiseizure effect in piriform cortex (McIntyre and Wong 1986) and hippocampus (Mueller and Dunwiddie 1983 ).

\section{Signal-to-noise ratio}

Computational modeling demonstrates that the suppression of excitatory synaptic transmission between pyramidal cells effectively enhances the signal-to-noise ratio in response to input. Thus the noradrenergic suppression of synaptic potentials shown here could contribute to the frequent observation of enhanced signal-to-noise ratio during activation of noradrenergic receptors in cortical structures.

These results can be used in consideration of results from a wide range of physiological experiments. For example, our modeling suggests that the enhancement of response to somatosensory afferent input during iontophoretic application of norepinephrine (Waterhouse and Woodward 1980) could be partially due to the suppression of excitatory synaptic transmission in somatosensory cortex (Dodt et al. 1991). The possibility that noradrenergic suppression is selective for particular subsets of synapses in neocortex as well as piriform cortex is supported by data showing selective noradrenergic innervation of different layers in the neocortex (Morrison et al. 1982). In addition, the decrease in background activity reported in the hippocampus during noradrenergic modulation (Curet and de Montigny 1988; Segal and Bloom 1974, 1976) could be due to suppression of excitatory transmission at synapses in region CA3 or CA1 of the hippocampus (Mody et al. 1983; Scanziani et al. 1994). Application of norepinephrine also has been shown to enhance the response of cortical neurons to sensory stimuli in other modalities, including auditory (Foote et al. 1983) and visual (Kasamatsu and Heggelund 1982; Madar and Segal 1980). Acetylcholine has an effect on synaptic transmission similar to that of norepinephrine. This suggests that acetylcholine should likewise enhance responsiveness to afferent input relative to intrinsic activity. Evidence for cholinergic enhancement of the response to sensory stimuli has in fact been demonstrated in the primary visual cortex (Sillito 


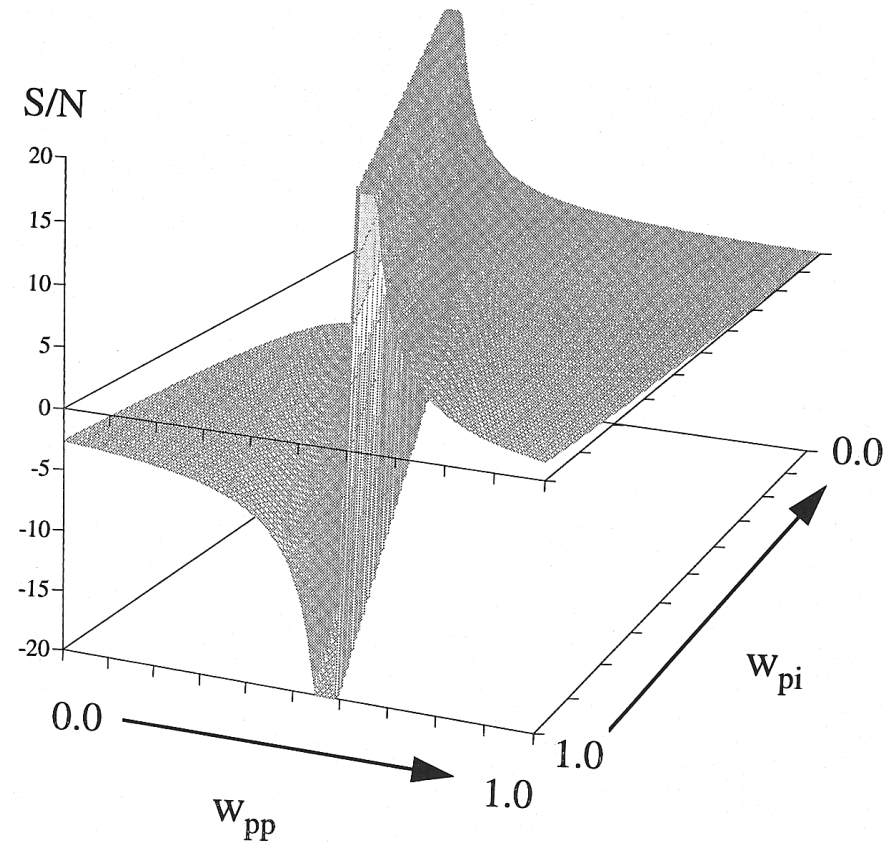

FIG. 10. Surface plot of signal-to-noise ratio changes across a wide range of values as generated by mathematical analysis presented in RESULTS . Note that $w_{\mathrm{pp}}$ decreases to left in this plot, whereas in Fig. 9, $w_{\mathrm{pp}}$ decreases to right. In this representation, decreases in excitatory connections between pyramidal cells $\left(w_{\mathrm{pp}}\right)$ can enhance signal-to-noise ratio for a range of values of excitatory input to interneurons $\left(w_{\mathrm{pi}}\right)$, but magnitude of effect depends on relationship of $w_{\mathrm{pp}}$ with $w_{\mathrm{pi}}$. Additional features of spiking model cause lower values of $s / n$ for high and low levels of $w_{\mathrm{pi}}$.

and Kemp 1983) and in auditory cortex (Ashe and Weinberger 1991; Metherate and Weinberger 1990).

Other cellular effects of norepinephrine also could contribute to the change in signal-to-noise ratio (see review of these effects in Hasselmo 1995). For example, experiments have demonstrated noradrenergic suppression of inhibitory synaptic potentials (Doze et al. 1991; Jahr and Nicoll 1982; Trombley and Shepherd 1991). In both the olfactory bulb and the hippocampus, the disinhibition appears to be primarily due to suppression of excitatory synaptic transmission from pyramidal cells to interneurons (Doze et al. 1991; Trombley and Shepherd 1991). In our model, suppression of excitatory synapses between pyramidal cells increases the signal-to-noise ratio of these cells but does not increase their average firing rates in response to external input. However, if excitatory input from pyramidal cells to inhibitory neurons also is reduced, pyramidal cells respond more strongly to afferent input and the signal-to-noise ratio is further enhanced. The parameter values for a maximal enhancement of the signal-to-noise ratio in the spiking network model lie in the range of the effects observed experimentally: $60 \%$ suppression of excitatory connections between pyramidal cells and $40 \%$ suppression of excitatory connections from pyramidal cells to interneurons.

Norepinephrine may directly influence the resting membrane potentials of interneurons (Doze et al. 1996) and pyramidal cells (Segal 1982). This appears to result in increases in spontaneous inhibitory synaptic potentials when recording from pyramidal cells in the piriform cortex (Gellman and Aghajanian 1993) and hippocampus (Doze et al. 1991).
We tested the effect of direct depolarization of neuronal membrane potential on signal-to-noise ratio but, surprisingly, did not see any significant effects of this depolarization on signal-to-noise ratio within the spiking network model.

The model presented here focuses on exploring specific cellular mechanisms for the change in signal-to-noise ratio. In contrast, previous modeling work on signal-to-noise ratio focused on modeling noradrenergic effects in specific behavioral paradigms rather than the cellular mechanisms for this change in signal-to-noise ratio (Cohen and Servan-Schreiber 1992; Servan-Schreiber et al. 1990). This previous work used connectionist networks to explore how changes in signal-to-noise ratio might influence behavioral function. In those models, changes in signal-to-noise ratio were modeled by changing the gain of a sigmoid input-output function, resulting in changes in network function corresponding to some of the behavioral effects observed in continuous performance tasks. This change may be a reasonable simplification of the change in circuit dynamics caused by norepinephrine and provides an effective framework for modeling behavioral paradigms, but it does not address the cellular phenomena underlying these changes in circuit dynamics.

The results presented here suggest that the phrase signalto-noise ratio may not be appropriate for describing the change in cortical dynamics induced by norepinephrine. In the context of the model presented here, what has been referred to previously as noise-the activity of cortical neurons not receiving afferent input-could be described instead as thought guided by previously formed representations, or expectation about upcoming stimuli in the environment, or interpretation based on the current internal interpretation of the world. Suppression of intrinsic and association fiber synaptic transmission by norepinephrine will decrease the influence of internal representations relative to afferent input. This change in focus from internal representations to outside stimuli can account for behavioral evidence for enhanced function in tasks testing "attention," and it could account for the enhanced accuracy of learning found during the increased release and decreased reuptake of norepinephrine induced by amphetamines. However, using the term noise implies that the background activity in the presence or absence of stimulation is random, neglecting its dependence on the structure of intrinsic excitatory connectivity.

\section{Relation to behavioral data}

Noradrenergic modulation appears to make afferent input the dominant influence on cortical dynamics. As described in previous theoretical work (Hasselmo 1995; Hasselmo and Bower 1993), enhancing the relative influence of afferent versus intrinsic excitation could be important for the storage of new information, preventing interpretation of sensory input based on previous learning from interfering with the formation of a new representation. In addition, the enhanced influence of afferent input could be important for enhancing the detection of subtle features of sensory stimuli. The proposal that noradrenergic modulation sets appropriate cortical dynamics for monitoring and storage of external stimulation is supported by single- and multiunit recording in the locus coeruleus. Locus coeruleus neurons show strong activity 
when automatic, tonic behaviors, such as sleep, grooming, or consumption, are interrupted and the animal orients toward the external environment (Aston-Jones 1985). Activity appears to match the level of vigilance directed toward the external environment (Aston-Jones and Bloom 1981a,b) In addition, lowest activity levels were noted during paradoxical sleep.

Thus physiological data suggests that norepinephrine should set the appropriate tone for storage and detection of salient behavioral information. This is supported by psychopharmacological work. Memory function can be impaired by blockers of adrenergic receptors (Hartley et al. 1983; Li and Mei 1994). Amphetamines, which enhance the release of norepinephrine, have been shown to enhance memory function in humans when administered before initial acquisition (Mewaldt and Ghonheim 1979) or immediately after acquisition (Soetens et al. 1995). In rats, amphetamines enhance retrieval when administered directly after acquisition or immediately before retrieval (Sara and Devauges 1989; Sara and Deweer 1982). The enhancement of retrieval may be due to greater sensitivity to sensory cues. Adrenergic agonists have been shown to enhance memory function in delayed-response tasks in primates (Arnsten and Contant 1992).

Within the olfactory system, noradrenergic modulation has been implicated in a number of behaviors. Encoding of male odors in mice appears to depend on noradrenergic innervation (Brennan et al. 1990), and olfactory learning in neonatal rats appears to be especially vulnerable to disruption of the noradrenergic system (Sullivan and Wilson 1994; Wilson et al. 1994) Aspects of this learning appear to involve noradrenergic influences on olfactory bulb responses (Wilson and Sullivan 1991), but noradrenergic influences in the piriform cortex also appear to be important, because olfactory bulb responses alone do not encode the reinforcement valency of odors (Sullivan and Wilson 1991). Lesion data shows that analysis of odor significance appears to involve structures further along in the olfactory system, including the amygdala and piriform cortex (Staubli et al. 1987; Sullivan and Wilson 1993). Thus noradrenergic effects in the piriform cortex may be important for the setting appropriate dynamics for storage of olfactory information.

\section{Effects of norepinephrine and acetylcholine}

As shown here, the selective suppression of excitatory synaptic transmission by norepinephrine is very similar to the selective suppression of transmission by acetylcholine (Hasselmo and Bower 1992). Many of the other effects of norepinephrine in cortical structures are similar to the effects of acetylcholine, including the suppression of neuronal adaptation (Barkai and Hasselmo 1994; Madison and Nicoll 1986), depolarization of pyramidal cell membrane potentials, the enhancement of spontaneous inhibitory potentials (Gellman and Aghajanian 1993; Patil and Hasselmo 1997), and the suppression of evoked inhibitory synaptic potentials (Doze et al. 1991; Patil and Hasselmo 1997). Considering its similarity with other effects of acetylcholine, it is perhaps not surprising that norepinephrine also enhances long-term potentiation in hippocampal region CA1 (Hopkins and Johnston 1988), the dentate gyrus and the neocortex (Brocher et al. 1992), similar to the enhancement of synaptic modification demonstrated during muscarinic receptor activation (Burgard and Sarvey 1990; Hasselmo and Barkai 1995; Huerta and Lisman 1993). Thus acetylcholine and norepinephrine may have similar modulatory influences on circuit dynamics.

Behavioral data suggest that acetylcholine and norepinephrine may have similar influences on normal memory function, allowing either endogenous substance to replace the effects of the other. Thus combined blockade of both muscarinic and noradrenergic receptors appears to influence memory function more strongly than blockade of individual receptors (Decker et al. 1990; Kobayashi et al. 1995), and amphetamines can decrease the encoding impairment caused by scopolamine (Mewaldt and Ghonheim 1979). However, memory deficits caused by lesions of cholinergic innervation in rats can be decreased by lesions of noradrenergic innervation, suggesting that a proper balance of neuromodulators is necessary (Sara et al. 1992). Studies on the primary visual cortex of cats suggest that both modulators are necessary for formation of ocular dominance columns during the critical period of visuocortical development (Bear and Singer 1986). Lesions of both cholinergic and noradrenergic fiber bundles passing dorsal to the corpus callosum block the reorganization of orientation columns, thereby preventing changes in ocular dominance due to the absence of visual input from an occluded eye.

As shown here, norepinephrine and acetylcholine do not cancel each other out, nor do they have a strong synergistic effect. Rather the combined dose of both modulators appears similar to a single dose of one modulator. These data and the similarities of effect of norepinephrine and acetylcholine raise the question of why separate modulators are necessary. However, regulatory mechanisms of noradrenergic influences have a completely different anatomy; differences between the two neuromodulators may not be so much in their physiology as in the pathways leading to their effects, allowing separate regulatory influences on the same set of effects. Noradrenergic innervation of the cortex arises primarily from the locus coeruleus (Foote et al. 1983), whereas cholinergic innervation of the cortex arises from a series of nuclei in the basal forebrain (see Mesulam et al. 1983 for review ): the neocortex receives innervation from the nucleus basalis of Meynert ( $\mathrm{Ch} 4)$, the piriform cortex receives innervation from the horizontal limb of the diagonal band of Broca (Ch3) (Gaykema et al. 1990; Wenk et al. 1977), and the hippocampus receives innervation from the vertical limb of the diagonal band of Broca ( $\mathrm{Ch} 2)$ and the medial septum (Ch1) (Frotscher and Leranth 1985; Gaykema et al. 1990). These anatomic pathways may be under very different regulatory influences, allowing separate mechanisms for the control of afferent versus intrinsic excitation. The locus coeruleus may be more selectively sensitive to general environmental context, whereas the cholinergic nuclei may play a role more directly related to the novelty or familiarity of specific sensory stimuli (Hasselmo 1995; Hasselmo and Schnell 1994; Hasselmo et al. 1995). Thus independent regulatory mechanisms may converge to modulate the cellular parameters underlying signal-to-noise ratio.

Address for reprint requests: M. Hasselmo, Dept. of Psychology, Rm. 984, Harvard University, 33 Kirkland St., Cambridge, MA 02138.

Received 30 October 1996; accepted in final form 19 February 1997. 


\section{REFERENCES}

Arnsten, A. F. T. And Contant, T. A. Alpha-2 adrenergic agonists decrease distractibility in aged monkeys performing the delayed response task. Psychopharmacology 108: 159-169, 1992.

Ashe, J. H. AND WeINBERGER, N. M. Acetylcholine modulation of cellular excitability via muscarinic receptors: functional plasticity in auditory cortex. In: Activation to Acquisition: Functional Aspects of the Basal Forebrain Cholinergic System, edited by R. T. Richardson. Boston, MA: Birkhauser, 1991, p. 189-246.

Aston-Jones, G. Behavioral functions of locus coeruleus derived from cellular attributes. Physiol. Psychol. 13: 118-126, 1985.

Aston-Jones, G. AND BloOM, F. E. Activity of norepinephrine-containing locus coeruleus neurons in behaving rats anticipates fluctuations in the sleep-waking cycle. J. Neurosci. 1: 876-886, 1981 a.

Aston-Jones, G. And Bloom, F. E. Norepinephrine-containing locus coeruleus neurons in behaving rats exhibit pronounced responses to nonnoxious environmental stimuli. J. Neurosci. 1: 887-900, 1981b.

BARKAI, E. AND Hasselmo, M. E. Modulation of the input/output function of rat piriform cortex pyramidal cells. J. Neurophysiol. 72: 644-658, 1994.

BeAR, M. F. AND Singer, W. Modulation of visual cortical plasticity by acetylcholine and noradrenaline. Nature Lond. 320: 172-176, 1986.

Brennan, P., KABA, H., AND KeVERnE, E. B. Olfactory recognition: a simple memory system. Science Wash. DC 250: 1223-1226, 1990.

Brocher, S., Artola, A., And Singer, W. Agonists of cholinergic and noradrenergic receptors facilitate synergistically the induction of longterm potentiation in slices of rat visual cortex. Brain Res. 573: 27-36, 1992.

Burgard, E. C. And SARvey, J. M. Muscarinic receptor activation facilitates the induction of long-term potentiation (LTP) in the rat dentate gyrus. Neurosci. Lett. 116: 34-39, 1990.

CoHen, J. D. And Servan-SchreIBER, D. Context, cortex and dopaminea connectionist approach to behavior and biology in schizophrenia. Psychol. Rev. 99: 45-77, 1992

Collins, G. G. S., Probett, G. A., Anson, J., and Mclaughlin, N. J. Excitatory and inhibitory effects of noradrenaline on synaptic transmission in the rat olfactory cortex slice. Brain Res. 299: 211-223, 1984.

Curet, O. AND DE MonTigny, C. Electrophysiological characterization of adrenoceptors in the rat dorsal hippocampus. I. Receptors mediating the effect of microintophoretically applied norepinephrine. Brain Res. 475: $35-46,1988$.

Decker, M. W., Gill, T. M., And McGaugh, J. L. Concurrent muscarinic and b-adrenergic blockade in rats impairs place-learning in a water maze and retention of inhibitory avoidance. Brain Res. 513: 81-85, 1990.

Dodt, H.-U., Pawelzik, H., And Zieglgansberger, W. Actions of noradrenaline on neocortical neurons in vitro. Brain Res. 545: 307-311, 1991.

Doze, V. A., Bergles, D. E., Smith, S. J., And Madison, D. V. Norepinephrine differentially regulates synaptic inhibition in the rat hippocampus. Soc. Neurosci. Abstr. 21: 1096, 1996.

Doze, V. A., Cohen, G. A., And Madison, D. V. Synaptic localization of adrenergic disinhibition in the rat hippocampus. Neuron 6: 889-900, 1991.

Foote, S. L., Bloom, F. E., And Aston-Jones, G. Nucleus locus coeruleus: new evidence of anatomical and physiological specificity. Physiol. Rev. 63: 844-913, 1983.

Frotscher, M. AND Leranth, C. Cholinergic innervation of the rat hippocampus as revealed by choline acetyltransferase immunocytochemistry: a combined light and electron microscopic study. J. Comp. Neurol. 239: 237-246, 1985.

Gaykema, R.P.A., Luiten, P.G.M., Nyakas, C., And Traber, J. Cortical projection patterns of the medial septum-diagonal band complex. $J$. Comp. Neurol. 293: 103-124, 1990.

Gellman, R. L. And Aghajanian, G. K. Pyramidal cells in piriform cortex receive a convergence of inputs from monoamine activated gabaergic interneurons. Brain Res. 600: 63-73, 1993.

HABERLY, L. B. Neuronal circuitry in olfactory cortex: anatomy and functional implications. Chem. Senses 10: 219-238, 1985.

HABERLy, L. B. AND Bower, J. M. Olfactory cortex: model circuit for study of associative memory? Trends Neurosci. 12: 258-264, 1989.

Hartley, L. R., Ungapen, S., Davie, I., And Spencer, D. J. The effect of beta adrenergic blocking drugs on speakers' performance and memory. Br. J. Psychiat. 142: 512-517, 1983.
Hasselmo, M. E. Neuromodulation and cortical function: modeling the physiological basis of behavior. Behav. Brain Res. 67: 1-27, 1995.

HASSElmo, M. E. AND BARKAI, E. Cholinergic modulation of activity-dependent synaptic plasiticity in the piriform cortex and associative memory function in a network biophysical simulation. J. Neurosci. 15: 65926604, 1995.

Hasselmo, M. E. AND Bower, J. M. Selective suppression of afferent but not intrinsic fiber synaptic transmission by 2-amino-4-phophonobutyric acid (AP4) in piriform cortex. Brain Res. 548: 248-255, 1991.

Hasselmo, M. E. AND Bower, J. M. Cholinergic suppression specific to intrinsic not afferent fiber synapses in rat piriform (olfactory) cortex. $J$. Neurophysiol. 67: 1222-1229, 1992.

Hasselmo, M. E. And Bower, J. M. Acetylcholine and memory. Trends Neurosci. 16: 218-222, 1993.

Hasselmo, M. E. And Schnell, E. Laminar selectivity of the cholinergic suppression of synaptic transmission in rat hippocampal region CA1: computational modeling and brain slice physiology. J. Neurosci. 14: 3898-3914, 1994.

Hasselmo, M. E., Schnell, E., And Barkai, E. Dynamics of learning and recall at excitatory recurrent synapses and cholinergic modulation in rat hippocampal region CA3. J. Neurosci. 15: 5249-5262, 1995.

Hasselmo, M. E. AND CEKIC, M. Suppression of synaptic transmission may allow combination of associative feedback and self-organizing feedforward connections in the neocortex. Behav. Brain Res. 79: 153-161, 1996.

Hopkins, W. F. AND Johnston, D. Noradrenergic enhancement of longterm potentiation at mossy fiber synapses in the hippocampus. J. Neurophysiol. 59: 667-687, 1988.

Huerta, P. T. AND Lisman, J. E. Heightened synaptic plasticity of hippocampal CA1 neurons during a cholinergically induced rhythmic state. Nature Lond. 364: 723-725, 1993.

JAHR, C. E. AND NiCOLL, R. A. Noradrenergic modulation of dendrodendritic inhibition in the olfactory bulb. Nature Lond. 297: 227-229, 1982.

Kasamatsu, T. And Heggelund, P. Single cell responses in cat visual cortex to visual stimulation during iontophoresis of noradrenaline. Exp. Brain Res. 45: 317-324, 1982.

Kobayashi, M., Ohno, M., Yamamoto, T., and Watanabe, S. Concurrent blockade of b-adrenergic and muscarinic receptors disrupts working memory but not reference memory in rats. Physiol. Behav. 58: 307-314, 1995.

Li, B.-M. AND MEI, Z.-T. Delayed-response deficit induced by local injection of the a-adrenergic antagonist yohimbine into the dorsolateral prefrontal cortex in young adult monkeys. Behav. Neural Biol. 62: 134139, 1994.

Linster, C. AND Hasselmo, M. E. Olfactory delayed-match-to-sample in a combined model of olfactory bulb and cortex. In: Computational Neuroscience, edited by J. M. Bower. Boston, MA: Academic, 1996.

Linster, C. And Hasselmo, M. E. Modulation of inhibition in a model of olfactory bulb reduces overlap in the neural representation of olfactory stimuli. Behav. Brain Res. 84: 117-127, 1997.

MADAR, Y. AND SEGAL, M. The functional role of the noradrenergic system in the visual cortex: activation of the noradrenergic pathway. Exp. Brain Res. 41: 814, 1980.

MAdison, D. V. AND NiCOLL, R. A. Actions of noradrenaline recorded intracellularly in rat hippocampal CA1 pyramidal cells, in vitro. J. Physiol. Lond. 372: 221-244, 1986.

Madison, D. V. And Nicoll, R. A. Norepinephrine decreases synaptic inhibition in the rat hippocampus. Brain Res. 442: 131-138, 1988.

MCINTYRe, D. C. AND Wong, R.K.S. Cellular and synaptic properties of amygdala-kindled pyriform cortex in vitro. J. Neurophysiol. 55: 12951307, 1986.

Mesulam, M.-M., Mufson, E. J., Wainer, B. H., And Levey, A. I. Central cholinergic pathways in the rat: an overview based on an alternative nomenclature (Ch1-Ch6). Neuroscience 10: 1185-1201, 1983.

Metherate, R. and Weinberger, N. M. Cholinergic modulation of responses to single tones produces tone-specific receptive-field alterations in cat auditory-cortex. Synapse 6: 133-145, 1990.

Mewaldt, S. P. And GHOnheim, M. M. The effects and interactions of scopolamine, physostigmine and methamphetamine on human memory. Pharm. Biochem. Behav. 10: 205-210, 1979.

Mody, I., Leung, P., ANd Miller, J. J. Role of norepinephrine in seizurelike activity of hippocampal pyramidal cells maintained in vitro: alteration by 6-hydroxydopamine lesions of norepinephrine-containing systems. Can. J. Physiol. Pharmacol. 61: 841-846, 1983.

Morrison, J. H., Foote, S. L., Molliver, M. E., Bloom, F. E., AND Lidov, 
H. G. D. Noradrenergic and serotonergic fibers innervate complementary layers in monkey primary cortex: an immuno-histochemical study. Proc. Natl. Acad. Sci. USA 79: 2401-2405, 1982.

Mueller, A. J., Hoffer, B. J., AND Dunwiddie, T. V. Noradrenergic responses in rat hippocampus: evidence for mediation by a and $\mathrm{b}$ receptors in the in vitro slice. Brain Res. 214: 113-126, 1981.

Mueller, A. L. AND Dunwiddie, T. V. Anticonvulsant and proconvulsant actions of a- and beta-noradrenergic agonists on epileptiform activity in rat hippocampus in vitro. Epilepsia. 24: 57-64, 1983.

MynliefF, M. AND DunwidDIE, T. V. Noradrenergic depression of synaptic responses in hippocampus of rat: evidence for mediation of alpha1-receptors. Neuropharmacology 27: 391-398, 1988.

Patil, M. And Hasselmo, M. E. Cholinergic modulation of synaptic inhibition and the role of interneurons in the piriform cortex. In: Computational Neuroscience, edited by J. M. Bower. New York: Academic. In press.

SARA, S. J. The locus coeruleus and cognitive function: attempts to relate noradrenergic enhancement of signal/noise in the brain to behavior. Physiol. Psychol. 13: 151-162, 1985.

SARA, S. J. AND Devauges, V. Idazoxan, an alpha-2 antagonist, facilitates memory retrieval in the rat. Behav. Neural Biol. 51: 401-411, 1989.

SARA, S. J. AND DEWEER, B. Memory retrieval enhanced by amphetamine after a long retention interval. Behav. Neural. Biol. 26: 146-160, 1982.

Sara, S. J., Dyonlaurent, C., Guibert, B., And Leviel, V. Noradrenergic hyperactivity after partial fornix section-role in cholinergic dependent memory performance. Exp. Brain Res. 89: 125-132, 1992.

Scanziani, M., Gahwiler, B. H., AND Thompson, S. M. Presynaptic inhibition of excitatory synaptic transmission mediated by a adrenergic receptors in area CA3 of the rat hippocampus in vitro. J. Neurosci. 13: 53435401, 1994.

SEGAL, M. The action of norepinephrine in the rat hippocampus: intracellular studies in the slice preparation. Brain Res . 206: 107-128, 1982.

Segal, M. And Bloom, F. E. The action of norepinephrine in the rat hippocampus. II. Activation of the input pathway. Brain Res. 72: 99-114, 1974.

SEgAL, M. AND Bloom, F. E. The action of norepinephrine in the rat hippocampus. III. Hippocampal cellular response to locus coeruleus stimulation in the wawake rat. Brain Res. 107: 513-525, 1976.

Servan-Schreiber, D., Printz, H., And Cohen, J. D. A network model of catecholamine effects - gain, signal-to-noise ratio and behavior. Science Wash. DC 249: 892-895, 1990

Sillito, A. M. AND Kemp, J. A. Cholinergic modulation of the functional organization of the cat visual cortex. Brain Res. 289: 143-155, 1983.

Soetens, E., Casaer, S., D'hooge, R., and Hueting, J. E. Effect of amphetamine on long-term retention of verbal material. Psychopharmacology 119: 155-162, 1995.

Staubli, U., Schottler, F., And Nejat-Bina, D. Role of dorsomedial thalamic nucleus and piriform cortex in processing olfactory information. Behav. Brain Res. 25: 117-129, 1987.

Sullivan, R. M. AND Wilson, D. A. Neural correlates of conditioned odor avoidance in infant rats. Behav. Neurosci. 105: 307-312, 1991.

Sullivan, R. M. AND Wilson, D. A. Role of the amygdala complex in early olfactory associative learning. Behav. Neurosci. 107: 254-263, 1993.

Sullivan, R. M. AND Wilson, D. A. The locus-coeruleus, norepinephrine and memory in newborns. Brain Res. Bull. 35: 467-472, 1994.

Tang, A. C. And Hasselmo, M. E. Selective suppression of intrinsic but not afferent fiber synaptic transmission by baclofen in the piriform (olfactory) cortex. Brain Res. 659: 75-81, 1994.

Trombley, P. Q. AND ShePherd, G. M. Noradrenergic inhibition of synaptic transmission between mitral and granule cells in mammalian olfactory bulb cultures. J. Neurosci. 12: 3985-3991, 1991.

TSENG, G.-F. AND HABERLY, L. B. Characterization of synaptically mediated fast and slow inhibitory processes in piriform cortex in an in vitro slice preparation. J. Neurophysiol. 59: 1352-1376, 1988.

Tseng, G.-F. And Haberly, L. B. Deep neurons in piriform cortex. II. Membrane properties that underlie unusual synaptic responses. J. Neurophysiol. 62: 386-400, 1989.

VANIER, M. C. AND BowER, J. M. Differential effects of norepinephrine on field potentials in layers $1 \mathrm{~A}$ and $1 \mathrm{~B}$ of rat olfactory cortex. Soc. Neurosci. Abstr. 18: 1353, 1992.

VANIER, M. C. AND Bower, J. M. Differential effects of norepinephrine on synaptic transmission layers $1 \mathrm{~A}$ and $1 \mathrm{~B}$ of rat olfactory cortex. In: Computation and Neural Systems, edited by F. H. Eeckman and J. M. Bower. Boston, MA: Kluwer Academic Publishers, 1993, p. $267-$ 272

WATERHOUSE, B. D. AND WoOdWARD, D. J. Interaction of norepinephrine with cerebrocortical activity evoked by stimulation of somatosensory afferent pathways in the rat. Exp. Neurol. 67: 11-34, 1980.

Wenk, H., Meyer, U., AND Bigl, V. Centrifugal cholinergic connections in the olfactory system of rats. Neuroscience 2: 797-800, 1977.

Wilson, D. A., Pham, T. C., And Sullivan, R. M. Norepinephrine and posttraining memory consolidation in neonatal rats. Behav. Neurosci. 108: 1053-1058, 1994.

Wilson, D. A. AND Sullivan, R. M. Olfactory associative conditioning in infant rats with brain stimulation as reward. II. Norepinephrine mediates a specific component of the bulb response to reward. Behav. Neurosci. 105: 843-849, 1991.

Wilson, H. R. AND CowAN, J. D. Excitatory and inhibitory interactions in localized populations of model neurons. Biophys. J. 12: 1-24, 1972.

Woodward, D. J., Moises, H. C., Waterhouse, B. D., Hoffer, B. J., AND FREEDMAN, R. Modulatory actions of norepinephrine in the central nervous system. Federation Proc. 38: 2109-2116, 1979. 